\title{
Application of Laser-Induced Fluorescence in Functional Studies of Photosynthetic Biofilms
}

\author{
Jorge Marques da Silva ${ }^{1, *(1)}$ and Andrei Borissovitch Utkin ${ }^{2,3}$ \\ 1 Department of Plant Biology and Biosystems and Integrative Sciences Institute (BioISI), Faculty of Sciences, \\ Universidade de Lisboa, Campo Grande, 1749-016 Lisbon, Portugal \\ 2 INOV INESC Inovação, Rua Alves Redol 9, 1000-029 Lisbon, Portugal; andrei.utkin@inov.pt \\ 3 Center of Physics and Engineering of Advanced Materials, Instituto Superior Técnico, \\ Universidade de Lisboa, Av. Rovisco Pais 1, 1049-001 Lisbon, Portugal \\ * Correspondence: jmlsilva@fc.ul.pt; Tel.: +351-217-500-000
}

Received: 18 October 2018; Accepted: 13 November 2018; Published: 19 November 2018

check for updates

\begin{abstract}
Biofilms are a ubiquitous form of life for microorganisms. Photosynthetic biofilms such as microphytobenthos (MPB) and biological soil crusts (BSC) play a relevant ecological role in aquatic and terrestrial ecosystems, respectively. On the other hand, photosynthetic epilithic biofilms (PEB) are major players in the microbial-induced decay of stone structures of cultural heritage. The use of fluorescence techniques, namely, pulse-amplitude-modulated fluorometry, was crucial to understanding the photophysiology of these microbial communities, since they made it possible to measure biofilms' photosynthetic activity without disturbing their delicate spatial organization within sediments or soils. The use of laser-induced fluorescence (LIF) added further technical advantages, enabling measurements to be made at a considerable distance from the samples, and under daylight. In this Perspective, we present state-of-the-art LIF techniques, show examples of the application of LIF to MPB and present exploratory results of LIF application to BSC, as well as to PEB colonizing stone structures of cultural heritage. Thereafter, we discuss the perspectives of LIF utilization in environmental research and monitoring, in cultural heritage conservation and assessment, and in biotechnological applications of photosynthetic biofilms.
\end{abstract}

Keywords: fluorescence; spectroscopy; laser; biofilm; photosynthesis

\section{Introduction}

The decay of excited chlorophyll molecules may occur through thermal dissipation, photochemical energy conversion or fluorescence emission [1]. The competition between photochemical energy conversion and fluorescence emission allows the use of the latter as a non-invasive proxy for photosynthesis [2] in higher plants [3], microalgae [4] and photosynthetic bacteria [5]. Microorganisms, either prokaryotic or eukaryotic, are often embedded in an extracellular polymeric matrix, adhering to different surfaces, forming biofilms, which most commonly are heterotrophic but may also be autotrophic [6]. In microphytobenthos (MPB), a eukaryotic diatom-dominated photosynthetic biofilm with a very relevant ecological role in estuarine ecosystems, the use of chlorophyll fluorescence techniques has been instrumental to unravel the photosynthetic performance [7], since they made it possible to assess biofilms' photosynthetic activity without disturbing their critical spatial organization within sediments. More recently, the use of fluorescence imaging techniques added the possibility of understanding the spatial heterogeneity of the photosynthetic activity in biofilms [8]. The application of fluorescence techniques to another type of photosynthetic biofilm, the prokaryotic terrestrial biological soil crusts (BSC), is just starting [9]. The use of fluorescence techniques in the study of terrestrial photosynthetic epilithic biofilms (PEB) is also novel. Chlorophyll fluorescence can be induced either 
by a lamp or a laser. The use of laser-induced fluorescence (LIF) brought further advances in the study of photosynthetic biofilms, as it allows measurements under daylight and at a considerable distance from the samples. In this Perspective, we present the state-of-the-art in LIF techniques and show examples of their application to MPB. In addition, we present exploratory results of LIF application to BSC and PEB. To conclude, we discuss the perspectives of LIF utilization in environmental research and monitoring, in cultural heritage conservation and assessment, as well as in biotechnological applications of photosynthetic biofilms.

\section{Laser-Induced Fluorescence (LIF)}

A typical setup used for LIF measurements is shown in Figure 1. Fluorescence is excited by a pulsed laser with a pulse duration of several nanoseconds. The most commonly used source is an Nd:YAG Q-switched solid-state laser emitting at the wavelength of 355 or $532 \mathrm{~nm}$ (correspondingly, in the frequency-tripled or -doubled mode): it combines robustness and low fabrication and maintenance costs with high electrical-to-optical power efficiency and significant quantum yield. The freshly emitted laser pulse irradiates the sample and excites the fluorescence emission. A part of this emission is collected by light-gathering optics, which can easily be developed based on off-the-shelf low-cost collimators (e.g., several F810SMA collimation packages, optimized for specific but rather wide wavelength regions [10]). To prevent backscattered laser radiation from entering the collimator and saturating or damaging the spectrometer, a longpass filter, with a cut-off wavelength slightly larger than the operating wavelength of the laser, is introduced into the optical path, in front of the front light-gathering lens. The collected and collimated radiation is transferred to a computer-controlled spectrometer.

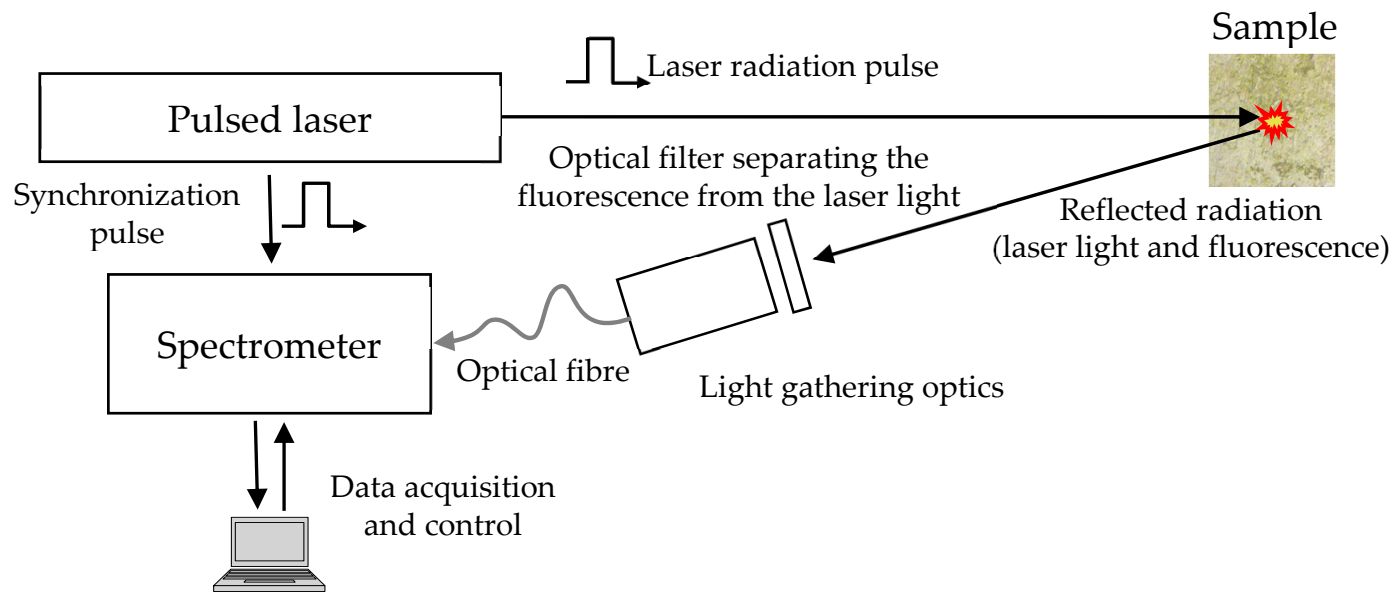

Figure 1. Setup for laser-induced fluorescence (LIF) measurements.

Until the 2000s, the development of LIF analyzers was hindered by manufacturing and maintenance costs of laser sources and spectrometers. Sensible spectrometers were generally based on a high-groove-density, echelle diffraction grating or similar optical device, assembled with an intensified or low-noise (often thermoelectrically cooled) camera. Such assemblages were usually bulky, about half a meter long, requiring at the same time an extremely precise positioning of the camera with respect to the diffraction grating. Therefore, the pieces had to be mounted on a thick and rigid metal plate, which dramatically increased the analyzer weight. A typical representative of the family of such instruments is the Spectrelle ${ }^{\circledR} 5000$ Compact high-resolution echelle spectrograph by GWU-Lasertechnik, Erftstadt, Germany [11].

The early 2010s witnessed a significant advancement of the LIF technology due to several breakthroughs in the development of spectral instrumentation, which resulted in the appearance of a variety of robust, low-cost palm-size spectrometers possessing high spectral resolution and sensitivity [12-14]. Remarkably, the spectrometers are manufactured for a wide range of diverse 
applications, each of which imposes specific requirements to the characteristics of the instrument. For this reason, the choice of the spectrometer for the concrete application becomes a non-trivial task, involving making several crucial choices with respect to numerous components that the principal manufacturers offer to the user $[15,16]$. For this reason, below we briefly summarize the main aspects of the LIF spectrometer selection, bearing in mind the following specificities:

- the early detection and evaluation of biofilms may require a high overall sensitivity of the sensor;

- the characteristic peaks due to the biofilm fluorescence are relatively wide, with the FWHM (full width at half maximum) of the order of tens of nanometers;

- the instrument for the field measurements must be robust and of low power consumption.

A basic spectrometer design comprises an input pupil, a diffraction grating and a photodetector. Depending on the application requirements, several additional components like mirrors, filters, lenses and a microprocessor controlling the acquisition and digitalization of data can be added to the basic scheme. As the LIF efficiency is several orders of magnitude lower than the elastic light scattering, fluorescence spectrometers necessitate very accurate synchronization of the measurement interval with the moment of emission of the excitation laser pulse, which has a duration of few nanoseconds. For this reason, most of the LIF measurement setups use direct synchronization of the spectrometer with the pulsed-laser Q-switch, bypassing the control computer software. When the computer application requests the spectrometer's microprocessor to start the measurements, it waits for the laser synchronization pulses and initiates the acquisition of fluorescence emission, collecting and sending to the application the requested number of digitally recorded spectra to be processed.

The spectrometer may possess an input slit establishing a trade-off between the sensitivity and the spectral resolution capacity: the wider the slit, the more light enters the spectrometer and the less the spectral selectivity. Provided the LIF spectra in question are sufficiently smooth, it is a good practice to have a spectrometer more biased towards sensitivity, using a wide slit or no slit at all (in the latter case the beam dimension is constrained by the core of the transporting optical fiber) [16].

After entering the spectrometer, the light beam is dispersed in accordance with its spectral composition, forming a specific radiation pattern on the active area of the photodetector. The demand for compactness gave a new impetus to the long-known Czerny-Turner design of the spectrometer optical system $[17,18]$, which is based on two curved mirrors. The first mirror collimates the radiation beam and directs it to the grating, while the other focuses the dispersed radiation on the photodetector array. The cheapest fluorescence spectrometer configurations use standard aluminum-coated mirrors, while more expensive options of special coatings offer enhanced reflectivity $(\sim 95 \%)$ within a wide range of angles of incidence. Some of these coatings, such as SAG+ offered by Ocean Optics $[19,20]$, absorb a significant part of the ultraviolet light, additionally reducing the parasitic effect of excitation scattering. The diffraction grating should have good reflecting efficiency in the spectral range of interest, ca. 550 to $800 \mathrm{~nm}$, so that sufficient resolution at an affordable price is achieved for the groove density of $500-1200 \mathrm{~mm}^{-1}$. Focusing the dispersed radiation on the CCD array may be enhanced by an additional cylindrical collection lens, placed in front of the detector window to focus the light from a tall slit onto shorter detector pixels. A typical CCD array, like TCD1304AP by Toshiba, Tokyo, Japan [21] or ILX511B by Sony, Tokyo, Japan [22] contains circa 2000-4000 pixels-elementary photodetectors sensitive to light in the VIS/NIR spectral range of 400-1000 nm.

\section{Application of LIF in Plant Sciences}

The first reported attempt to use LIF spectroscopy to assess the photosynthetic physiology of plants was by Brach and co-workers [23] in lettuce (Lactuca sativa). First reports showed that laser-induced fluorescence spectra from leaves presented two emission peaks, a relative maximum in the red band ( $685 \mathrm{~nm}, \mathrm{~F} 685$ ) and an absolute maximum in the far-red band (circa $740 \mathrm{~nm}, \mathrm{~F} 740$ ). The relative intensity, shape and wavelength of those peaks were dependent on the physiological status of the plant's photosynthetic apparatus (reviewed by Buschmann [24]) and may reflect changes 
in leaf chlorophyll $a(\mathrm{Chl} a)$ concentration, which are frequent in plant stress situations [25-31]. Recently, using LIF technology, Lavrov et al. [32] showed that, in several forest species subjected to severe drought stress, the red/far-red fluorescence ratio (Fr/Ffr) was highly correlated with the maximum potential photochemical efficiency of photosystem II (PSII), estimated by the ratio between variable fluorescence and maximal fluorescence $(\mathrm{Fv} / \mathrm{Fm})$, measured with continuous fluorimetry. The simultaneous measurement of chlorophyll fluorescence by LIF and by pulse-amplitude-modulated (PAM) fluorescence was performed in maize (Zea mays), sugar beet (Beta vulgaris) and kalanchoë (Kalanchoë sp.), showing that LIF fluorescence was useful to detect plant water stress [33]. Only two reports on the application of LIF to the model plant Arabidopsis thaliana are available: one from Kolber and co-workers [34], who studied a npq mutant showing changes in the PS II PsbS protein, and a more recent one from Gameiro et al. [35], comparing the effects of rapidly and slowly induced water stress.

\section{Photosynthetic Biofilms}

Biofilms are microbial communities where cells occupy a thin layer over the surface of a substrate, or inhabit the interface between two substrates, and are immersed in an extracellular polymeric substances (EPS) matrix produced by them. Among the many types of biofilms, photoautotrophic ones (i.e., biofilms that include microorganisms able to synthesize organic compounds using light energy) play particularly relevant ecological roles. MPB is a eukaryotic diatom-dominated biofilm that is of significant importance for estuarine ecology [36]. In particular, the EPS excreted by MPB diatoms promote the aggregation of sediment particles, stabilizing intertidal estuarine mudflats [37]. A similar ecological role is played by the EPS produced by cyanobacteria of BSC in terrestrial ecosystems [38,39]. In rocky shores, PEB play a major role in primary production and are the energy base of the benthic food web [40].

Estuarine intertidal MPB inhabiting soft sediments are composed mainly by motile diatoms, which exhibit diel vertical migrations, connected to tidal cycles, within the sediment photic zone $[41,42]$. In spite of the key role played by these communities in estuarine productivity, their carbon economy is still under dispute [43], although a tight link with the heterotrophic bacterial community inhabiting intertidal mudflats has been established [44]. The hidden beauty of the diatoms-dominated benthic communities is unraveled under the microscope lens and has been praised by biologists [45], who named them "secret gardens" [36]. Although only accounting for a minor part, in comparison with others, the aesthetic value of MPB could also be counted as an ecosystem service, integrating the cultural services rendered by estuarine areas, as envisaged by Constanza and co-workers [46].

A similar ecological role is played in the terrestrial ecosystems by the EPS produced by BSC cyanobacteria [38]. Biological soil crusts, also known as biocrusts, microbiotic, cryptobiotic, cryptogamic or microphytic crusts, are complex communities of cyanobacteria, green algae, bryophytes, microfungi, lichens and other bacteria. Cyanobacterial filaments, fungal hyphae, and, sometimes, the rhizoids of mosses and lichens, present in the top few millimeters of soil, keep together the soil particles and form a matrix that stabilizes and protects the soil surface from wind and rain erosion. They also act as a living soil cover, maintaining soil moisture [39] and preventing the growth of annual weeds. Although demonstrating a diverse composition, this type of crusts occurs in all arid and semi-arid regions of the world, where they occupy nutrient-deficient areas, between patches of vegetation. In some plant communities they can form as much as $70 \%$ of soil cover, fixing atmospheric nitrogen and significantly contributing to soil organic matter. However, only recently the importance of BSC to terrestrial ecosystems has been recognized. Their role in biodiversity is also relevant, as in some arid ecosystems there are more species associated with the BSC than vascular plant species (Belnap et al. [47] and references therein). Bare soil is initially colonized by cyanobacteria. Later, if the environmental conditions are suitable, the ecological succession may progress to more structurally complex biological soil crusts, forming a rough and irregular carpet dominated by low $(1$ to $10 \mathrm{~cm})$ mosses. Here we will refer mainly to cyanobacteria-dominated BSC, typical of early stages of the succession of soil colonization. Although not often referred to as biofilms, they meet the criteria to be 
classified as such: they strive in a thin layer in the interface between soil and the atmosphere, and the bacterial cells are embedded in a self-produced EPS matrix.

Photosynthetic epilithic biofilms (PEB) are formed by an association of prokaryotic and eukaryotic microorganisms, both autotroph and heterotroph, typically exhibiting a remarkable diversity of metabolic pathways, that grow over rocks in freshwater streams [48]. They colonize both quiescent waters and streams with high shear rates [49], where they contribute substantially to biogeochemical processes [50]. PEB may also colonize terrestrial habitats, being common in stone buildings, where they may have a negative impact both on the physical structure and the appearance of the stone [51]. This is particularly relevant in cultural heritage buildings, where biodeterioration caused by biofilm formation has been reported [52]. Although microorganisms from the phylum Acidobacteria play a major role in biodeterioration of stone of cultural heritage, they are often associated with photosynthetic cyanobacteria that provide photoassimilates essential for their heterotrophic metabolism [53].

In addition to their importance for human health, cultural heritage, ecological processes and biotechnological applications, biofilms are genuine objects of deep scientific interest. The complexity of internal organization of some multispecies biofilms, including autotrophic biofilms, resembles multicellular organisms, raising the question of whether biofilms are evolutionary individuals, i.e., whether they are capable of evolutionary change $[54,55]$. Therefore, biofilms may help to solve some fundamental problems of theoretical biology and philosophy of biology.

\section{Application of LIF to Photosynthetic Biofilm}

Major advances in the understanding of the ecophysiology and productivity of MPB communities were achieved due to the application of PAM fluorometry $[7,56]$, as these techniques allowed for the first time the non-invasive estimation of biofilm's photosynthetic activity. Nonetheless, these techniques still present some limitations, such as the need for a close proximity between the MPB sample and the PAM fluorometer optical fibre.

On the contrary, LIF has been successfully used in medium- and long-range remote sensing of vegetation $[27,57,58]$. More recently, LIFT (laser-induced fluorescence transients) have been measured using devices able to operate at a distance reaching $50 \mathrm{~m}$ from the sample $[34,59,60]$. The application of LIF to photosynthetic biofilms, however, has been less common. To our knowledge, in its first application to MPB, LIF has been used as a remote sensing technique to study the MPB biomass at the intertidal mudflats of the Tagus estuary, in Portugal $[18,61,62]$. The authors succeed in using LIF to estimate MPB biomass and, in the case of epipelic communities, where diatoms show vertical migrations due to diel and tidal cycles and high irradiances, diatom movement was also successfully tracked. Figure 2 shows typical LIF spectra of MPB in mud and sand intertidal sediments.

Results were obtained from sediment samples collected at Alcochete, Tagus Estuary, Portugal $\left(38^{\circ} 44^{\prime} \mathrm{N}, 09^{\circ} 08^{\prime} \mathrm{W}\right)$. Sampling was carried out during low tide at two locals locations with different sediment types: a mud site with $97 \%$ of particles $<63 \mu \mathrm{m}$, and a sand site composed of a mixture of very fine to coarse sand ranging in diameter between 125 and $1000 \mu \mathrm{m}$ [61]. In vivo LIF spectra of sediment MPB communities were recorded in several independent samples collected on different occasions between February and July 2010 with an Nd:YAG laser providing 4-ns, 30-mJ pulses at the wavelength of $532 \mathrm{~nm}$. The distance of the laser to the sediment was approximately $1 \mathrm{~m}$ and the diameter of the laser spot at the sediment surface was circa $1.5 \mathrm{~cm}$ [61]. Emission spectra of mud sediments showed consistently higher laser-induced fluorescence intensities than those from the sand sediments. As seen from the figure, the red peak maximum was slightly higher in sand sediments (at the spectral position of $686.5 \mathrm{~nm}$ ) than in mud sediments (at $685.3 \mathrm{~nm}$ ). There was a positive correlation between peak area and the wavelength shift of peak maxima. This means that for areas of sediments with increased surface biomass there is a more pronounced shift of the red peak maxima to higher wavelengths. This is clearly visible in Figure 3, which presents the relative fluorescence spectra of three samples of MPB with different biomass in mud intertidal sediments. In fact, MPB may present marked spatial 
heterogeneity in its abundance and composition [63], and the samples used in Figure 3 were collected in different micro-sites of the Tagus estuary in order to reflect that heterogeneity.

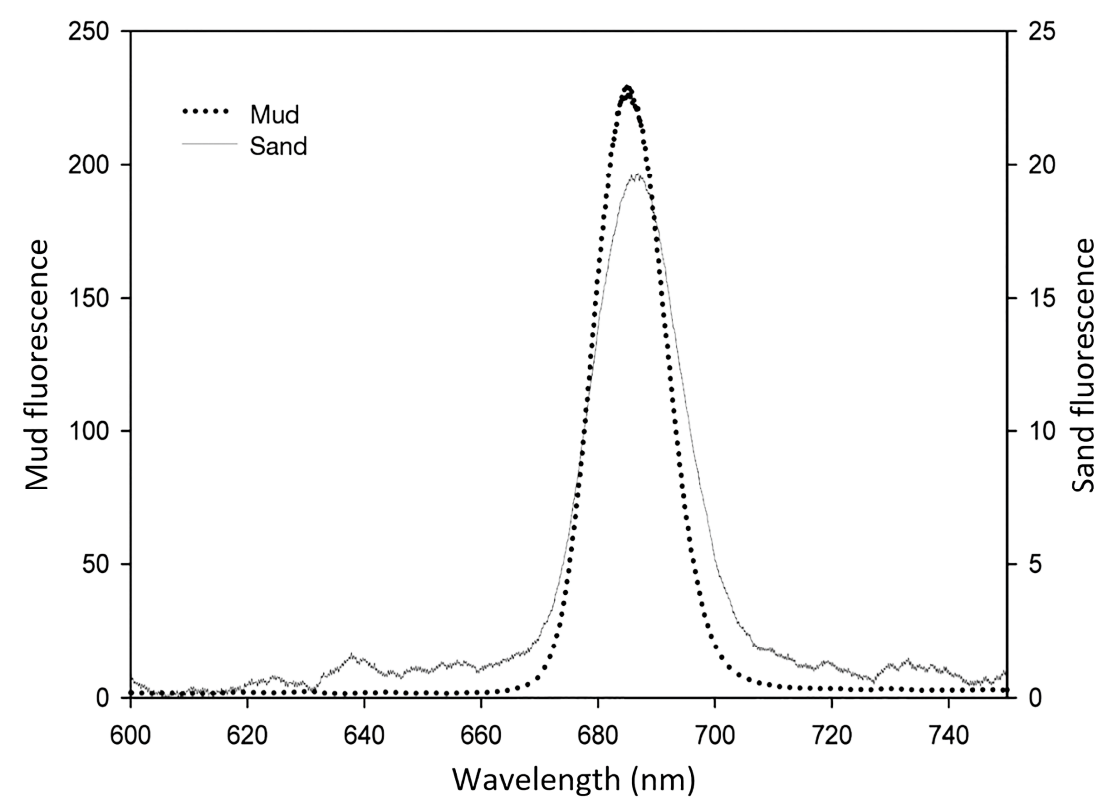

Figure 2. Typical LIF spectra of microphytobenthos in mud and sand intertidal sediments (reprinted from Vieira [61] with permission).

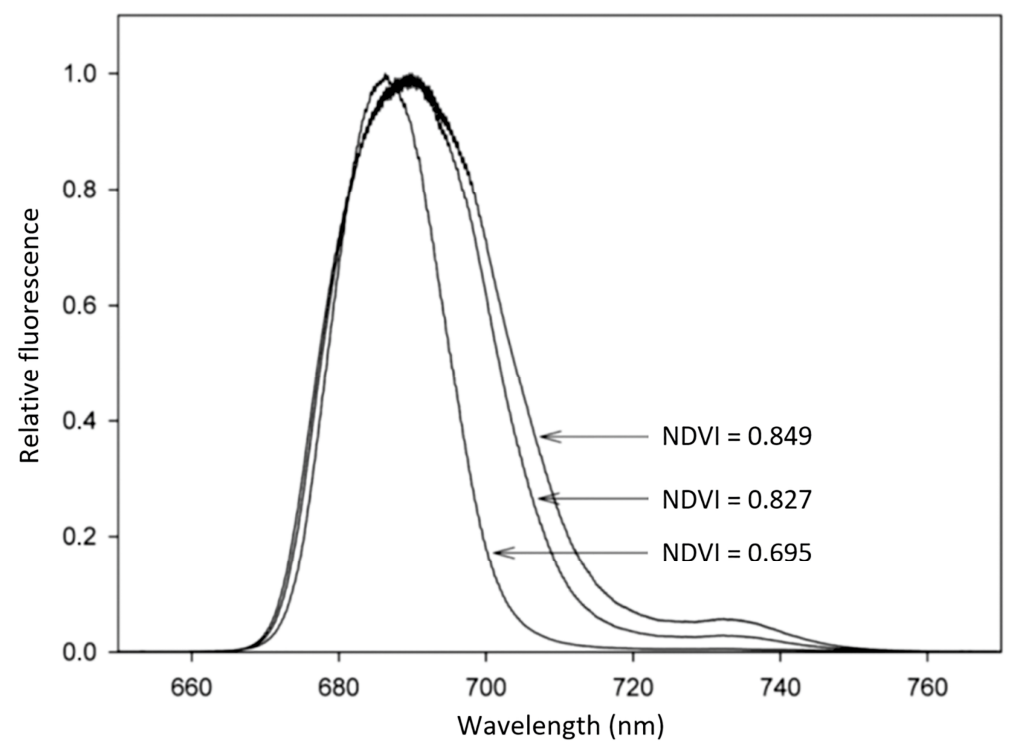

Figure 3. Relative fluorescence spectra of three samples of microphytobenthos (MPB) with different biomass in mud intertidal sediments (one sample with low biomass and two with high biomass). The normalized difference vegetation index (NDVI) is presented for the three samples (reprinted from Vieira [61] with permission).

The normalized difference vegetation index, NDVI $=\left(R_{750}-R_{675}\right) /\left(R_{750}+R_{675}\right)$, computed from the reflectance spectra of photosynthetic organisms at the wavelengths of $675 \mathrm{~nm}\left(\mathrm{R}_{675}\right)$ and $750 \mathrm{~nm}$ $\left(R_{750}\right)$, is a well-established index characterizing the photosynthetic biomass [64], frequently used to compare the biomass of MPB samples [65]. Reflectance spectra were measured over a 350 to $1000 \mathrm{~nm}$ bandwidth by means of a USB4000 spectrometer with a VIS-NIR optical configuration connected to a light-gathering system positioned perpendicular to the sediment surface, maintained at a fixed 
distance from the sample, and set to match the area measured by LIF. Sample spectra were measured under a constant irradiance of $70 \mu \mathrm{mol}$ photons $\mathrm{m}^{-2} \mathrm{~s}^{-1}$ [61]. NDVI was 0.695 for the sample with the LIF spectra with the lower integral area and a red emission peak at the lower wavelength, and 0.827 and 0.849 for the spectra with higher integrated areas and with red emission peaks at the higher wavelengths. A high correlation was found between NDVI and the peak area of LIF spectra, showing that LIF is a suitable technique to assess the biomass of MPB [62].

Figure 4 demonstrates the first (to the best of our knowledge) LIF spectra obtained from biological soil crusts, which markedly differ from the MPB spectra. In contrast to MPB, BSC present two main fluorescence peaks, one around $570 \mathrm{~nm}(a)$, the other around $650 \mathrm{~nm}(b)$, and a secondary peak around $720 \mathrm{~nm}(c)$. Slight deviations of peaks' maxima occur between dry and hydrated crusts, but the main difference between them is in the intensity of the peaks. Bare soil, either dry or hydrated, did not show any significant fluorescence. The difference between MPB (Figures 2 and 3) and BSC spectra (Figure 4) results from different dominating organisms in the two biofilms: MPB is dominated by diatoms, whereas BSC are dominated by cyanobacteria. These two types of organisms are very different, the former being eukaryotes and the latter prokaryotes. Although both undertake oxygenic photosynthesis, their photosynthetic apparatus differs in several ways, including the composition of photosynthetic pigments. Whereas diatoms have chlorophyll $a$ as the main photosynthetic pigment, and chlorophyll $c$ and carotenoids as the accessory photosynthetic pigments [66], cyanobacteria also present chlorophyll $a$ as the main pigment but include phycobilins as accessory pigments [67]. These always include phycocyanin and allophycocyanin and, in a group called red cyanobacteria, also phycoerythrin [68].

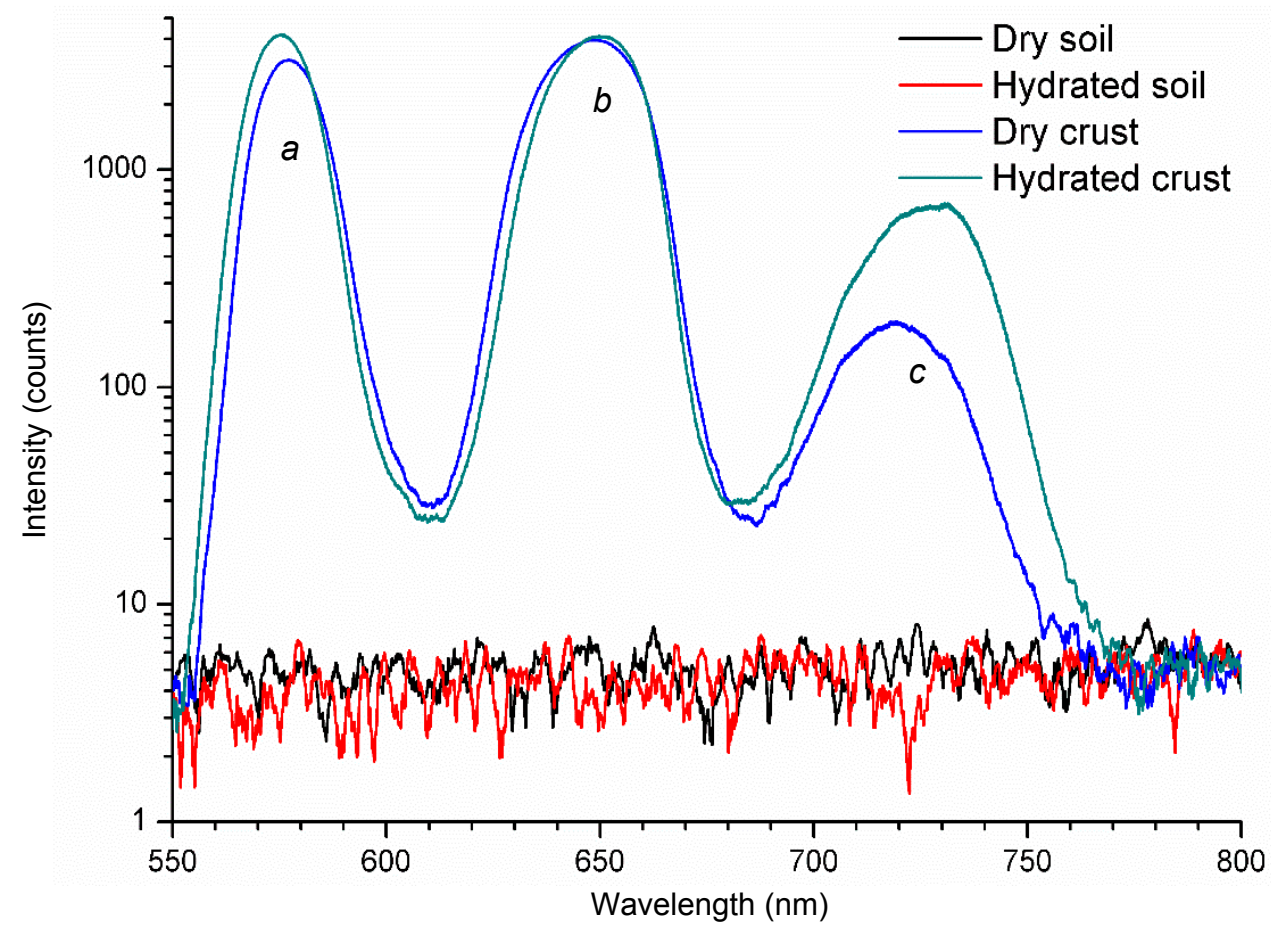

Figure 4. Laser-induced fluorescence spectra obtained from dry and hydrated soils and biological crusts. Each spectrum of the figure corresponds to a mean value obtained by averaging 128 returns from 7-ns laser pulses generated by a frequency-doubled Q-switched Nd:YAG laser [69] at the wavelength of $532 \mathrm{~nm}$. To avoid any damage to the photosynthetic apparatus of the plants under investigation, the chosen laser-to-sample distance provided the spot diameter at the surface location of about $1 \mathrm{~cm}^{2}$, which, with the selected laser pulse energy of 5-mJ, corresponds to the fluence of $5 \mathrm{~mJ} / \mathrm{cm}^{2}$, far below the damage threshold [18].

Fluorescence peak (a) (Figure 4) is probably due to the presence of phycoerythrin, which in vitro presents a fluorescence emission peak at $573 \mathrm{~nm}$. The cryptophyte Rhodomonas CS24., which has a 
photosynthetic antenna based in phycoerythrin, presents an in vivo fluorescence emission peak at 585 $\mathrm{nm}$ at room temperature [70]. Fluorescence peak $(b)$ is probably due to the presence of phycocyanins, which, in vitro at room temperature, present a single fluorescence emission peak around $650 \mathrm{~nm}$ [71]. Fluorescence peak $(c)$ is probably due to the presence of chlorophylls, albeit the far-red component (usually circa 730-740 nm) is markedly predominant over the red component (typically between 680-690 nm), in contrast with the results of MPB (Figure 2). However, the increase in this peak intensity in hydrated BSC suggests that it is in fact due to the presence of chlorophylls. We have previously found a marked increase in the basal fluorescence (Fo) of hydrated BSC measured with a PAM fluorometer, a device specifically designed for in vivo chlorophyll fluorescence measurements (unpublished results). The strong increase in fluorescence emission of hydrated crusts may reflect the activation of the photosynthetic apparatus. Most biocrusts' microorganisms are anhydrobiotic [72], meaning that they can withstand the loss of almost all their protoplasmic water, ceasing all metabolic activity, but rapidly resuming it after rehydration. The putative presence of significant amounts of phycocyanin, phycoerythrins and chlorophylls in the BSC analyzed suggests the presence in the biofilm microbial community of both blue and red cyanobacteria, as well as eukaryotic microorganisms (diatoms, green algae). These preliminary results suggest that LIF may be used to assess the microbial composition of biofilms, at least at the level of major groups of microorganisms.

The recent developments within the framework of the EU project STORM (Safeguarding Cultural Heritage through Technical and Organisational Resources Management) have demonstrated the successful application of the induced fluorescence technique to the detection of photosynthetic epilithic biofilms, at the early stages of their development, when they are invisible to the naked eye. The LIF setup configuration corresponds to that used for BSC analysis: 7-ns, 5-mJ pulses at $532 \mathrm{~nm}$ from the ULTRA laser produce the vegetation-safe radiation of the fluence of ca. $5 \mathrm{~mJ} / \mathrm{cm}^{2}$, and the induced emission is detected by a USB4000 spectrometer (by Ocean Optics, Winter Park, FL, USA). Several fragments of the plaster located in different places of the Early Christian basilica of Tróia, Portugal [73] were selected as characteristic samples and are subjected to monthly measurements.

A lichen-contaminated fragment of one such sample and corresponding fluorescence signature of the biofilm-comprising two characteristic peaks at ca. 690 and $707 \mathrm{~nm}$-are shown in Figure 5. These peaks are typical of chlorophyll $a$ fluorescence. The main peak at ca. $690 \mathrm{~nm}$ represents the commonly observed fluorescence emission of chlorophyll $a$ in the red region, whereas the secondary peak found at ca. $707 \mathrm{~nm}$ represents a shift of the typical emission of chlorophyll fluorescence in the far-red region of the spectrum [35]. In higher plants, the far-red fluorescence emission peak is circa $740 \mathrm{~nm}$, but there are interspecific variations. In Arabidopsis thaliana the peak was reported at $726.9 \mathrm{~nm}$ [35] and in sunflower at $725.4 \mathrm{~nm}$. However, nitrogen starvation caused a marked downshift of this peak to $716.4 \mathrm{~nm}$ [27], showing that the position of the in vivo fluorescence emission peak is not only species dependent, but also related to the environmental conditions. The shift of the in vivo chlorophyll fluorescence emission peaks may be due to changes in the amount of chlorophyll, alterations of the tissues' geometry and the presence of other chromophores (e.g., anthocyanins). Lichens are symbiotic associations of algae and fungi and therefore are able to produce uncommon pigments such as parietin and melanin [74] which may contribute to the shift of in vivo chlorophyll fluorescence emission peaks. 


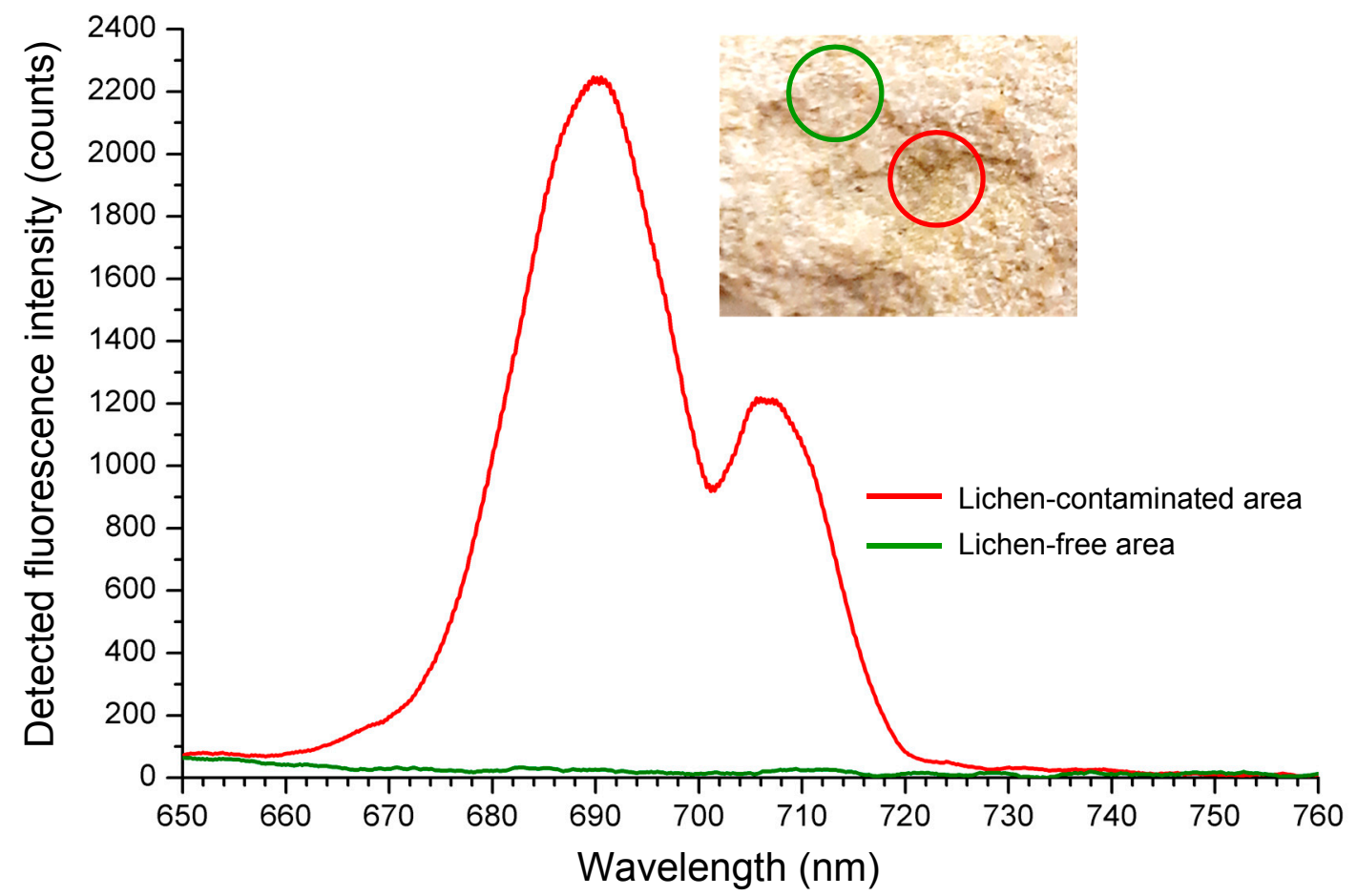

Figure 5. LIF spectra from the basilica wall, corresponding to emission from the lichen-contaminated (red) and lichen-free (green) areas.

\section{Future Prospects}

Estuaries lie at the interface between land and sea and are expected to suffer heavy impacts of climate change due to sea-level rise, increasing storm frequency and severity (extreme events), increased water temperature, coastal eutrophication and ocean acidification [75]. Therefore, there is a need to increase their environmental monitoring. On the other hand, the expansion of drylands [76] makes the understanding and conservation of BSC imperative, as they may contribute to prevent soil erosion and avoid dust storms, and increase soil fertility by contributing to carbon and nitrogen fixation. The inoculation of cyanobacteria to promote BSC development has been proposed as a new biotechnological tool to restore degraded areas and is currently actively researched in several laboratories [77]. The use of LIF in the study and environmental monitoring of habitats dominated by photosynthetic biofilms (e.g., intertidal mudflats, arid regions' soils, and epilithic biofilms of rocky shores) is expected to increase since (a) compact and less expensive laser systems are becoming more available and (b) the physiological interpretation of the phenomenology of LIF signals is increasingly improving. LIF technology may be used at an intermediate level between close range technologies (e.g., PAM fluorometry, which is able to in-depth depict the photosynthetic functional details of small spots of biofilms) and remote sensing provided by the new generation of earth observation satellites, with their increased capacity for remotely estimating ecosystem functions at large scales (e.g., photosynthetic production) [78]. LIF technology may provide both functional and taxonomic/ecological information on photosynthetic biofilms. The ratio between chlorophyll $a$ fluorescence emission in the red and the far-red bands of the spectrum correlates well with the photosynthetic activity/primary productivity of the biofilms, and the spectral signature reflects the presence of accessory photosynthetic pigments which are characteristic of certain groups of microorganisms. Therefore, LIF is able to discriminate between at least the major groups of photosynthetic microorganism present in a biofilm, which is extremely relevant from an ecological point of view. In fact, a major effect of climate change on both MPB [79] and BSC [80] is an increase of the importance of cyanobacteria as main primary producers.

Furthermore, present-day environmental changes and variation of climatic conditions are responsible for the deterioration of cultural heritage at an alarming rate. In particular, there is 
an increasing hazard linked to the rapid development of biofilms on the surface of wall paintings (frescos). We have shown that the LIF technique may become an important tool for the diagnosis and conservation of cultural heritage, in articulation with other spectroscopic techniques. In particular, we found to be promising the combination of LIF with the detection of two-dimensional spectral fluorescence signatures (SFS) using the fluorescence induction by a wide spectrum source (such as a pulsed xenon flashlamp) coupled with a monochromator, enabling the instrument to additionally scan the excitation wavelength [81]. The latter technique permitted the detection of not only the algae, moss, or lichen infestation, but also the non-chlorophyll-containing biofilms (such as fungi and bacteria), due to significant fluorescence emission of proteins in the vicinity of the point $280 / 325 \mathrm{~nm}$ on the excitation/emission wavelength plane $[82,83]$. This example clearly illustrates the complementarity and potential synergism between LIF and other techniques in the study of biofilms. Biofilms are increasingly seen as a useful resource in biotechnological applications. The use of photosynthetic biofilms, taking advantage of new reactor technologies, offers several vantages over cells in suspension. For example, the high density of the immobilized biocatalyst facilitates the separation between the catalyst and the product, significantly decreasing the expense of downstream processing [84]. Furthermore, some biotechnological uses of biofilms cannot be done in cell suspensions, and the formation of biofilms is mandatory. Microbial fuel cells are an emerging technology that uses microorganisms to metabolize organic substrates to produce electrical power. However, the energy balance of this process might not be favorable to industrial production, since it requires the use of energy-enriched organic substrates as raw materials. Fortunately, recent research showed that certain photosynthetic bacterial biofilms are capable of self-mediated extracellular electron transport, overcoming the need for organic substrates and therefore boosting the future development of renewable solar energy technologies. Besides cyanobacteria, green algae may also be used, but it is required that the microorganisms form a biofilm directly over the surface of a transparent, conductive anode [85]. The measurement of photosynthetic activity of intact biofilms with the instruments used in cell suspensions (e.g., Clarke-type oxygen electrodes [86]) is not feasible and their adaptation to use in biofilms [87] is not suited to be used in large scale and automation [7]. Therefore, the application of LIF to monitor and study photosynthetic biofilms used in biotechnological applications for electricity production or other purposes (e.g., biohydrogen production, wastewater treatment, bioremediation, fish-feed production, soil improvement, etc. [88]) is very promising.

Simultaneously, with the tremendous progress in the area of production of new optoelectronic materials, the availability of induced fluorescence methods increases at nearly the same pace as that of the information technologies. Remarkably, the advance affects both the radiation sources and the photodetectors: costly, heavy and bulky lasers are giving way to their compact, efficient and long-lifespan counterparts, based on robust mechanical design, high-purity crystals, new lasing media, etc. On the other hand, novel high-sensitivity photodetectors alleviate the requirement of the irradiation intensity, making it possible to implement the fluorescence sensor on the basis of more compact and less expensive sources, such as laser diodes and flashlamps. As was discussed, in the latter case one can obtain two-dimensional spectral fluorescence signatures of the object under investigation that are much more informative than the conventional spectra due to monochromatic irradiation. Apart from low dimensions, light weight and low fabrication costs, contemporary fluorescence sensors have a tendency to be more robust and require less maintenance due to better and more reliable electro-optical components (see, e.g., [89]). We foresee an enlarged application of the induced fluorescence spectroscopy to photosynthetic biofilms, both in environmental studies and monitorization and in biotechnological applications, as well as in cultural heritage conservation programs.

Author Contributions: J.M.S. and A.B.U. conceived, designed and performed the experiments and wrote the paper.

Funding: A part of this research related to microphytobenthos and biological soil crusts was funded by Fundação para a Ciência e Tecnologia, FCT/MCTES/PIDDAC, Portugal, through the projects PEst-OE/BIA/UI4046/2014 and UID/MULTI/00612/2013. Reported application of the induced fluorescence technique to the detection of 
photosynthetic epilithic biofilms was funded by the European Union's Horizon 2020 research and innovation programme under Grant Agreement No. 700191, project STORM (Safeguarding Cultural Heritage through Technical and Organisational Resources Management).

Acknowledgments: We are indebted to Sónia Vieira for allowing the reprint of Figures 2 and 3 and to Ricardo Cruz de Carvalho for providing the biological soil crusts used in the measurements shown in Figure 4.

Conflicts of Interest: The authors declare no conflict of interest. The founding sponsors had no role in the design of the study; in the collection, analyses, or interpretation of data; in the writing of the manuscript, and in the decision to publish the results.

\section{References}

1. Marques da Silva, J.; Bernardes da Silva, A.; Pádua, M. Modulated chlorophyll a fluorescence: A tool for teaching photosynthesis. J. Biol. Educ. 2007, 41, 178-183. [CrossRef]

2. Schreiber, U.; Schliwa, U.; Bilger, W. Continuous recording of photochemical and non-photochemical chlorophyll fluorescence quenching with a new type of modulation fluorometer. Photosynth. Res. 1986, 10, 51-62. [CrossRef] [PubMed]

3. Marques da Silva, J.; Arrabaça, M.C. Characteristics of fluorescence emission by leaves of nitrogen starved Paspalum dilatatum POIR. Photosynthetica 1992, 26, 253-256.

4. Serôdio, J.; Marques da Silva, J.; Catarino, F. Relationship between chlorophyll fluorescence quenching and $\mathrm{O}_{2}$ evolution in microalgae. In Photosynthesis: Mechanisms and Effects; Garab, G., Ed.; Kluwer Academic Publishers: Dordrecht, The Netherlands, 1998; Volume IV, pp. 2585-2588.

5. Campbell, D.; Hurry, V.; Clarke, A.K.; Gustafsson, P.; Öquist, G. Chlorophyll fluorescence analysis of cyanobacterial photosynthesis and acclimation. Microbiol. Mol. Biol. Rev. 1998, 62, 667-683. [PubMed]

6. Besemer, K.; Hödl, I.; Sikger, G.; Battin, T.J. Architectural differentiation reflects bacterial community structure in stream biofilms. ISME J. 2009, 3, 1318-1324. [CrossRef] [PubMed]

7. Serôdio, J.; Marques da Silva, J.; Catarino, F. Nondestructive tracing of migratory rhythms of intertidal benthic microalgae using in vivo chlorophyll $a$ fluorescence. J. Phycol. 1997, 33, 542-553. [CrossRef]

8. Vieira, S.; Ribeiro, L.; Jesus, B.; Cartaxana, P.; Marques da Silva, J. Photosynthesis assessment in microphytobenthos with conventional and imaging pulse amplitude modulation fluorometry. Photochem. Photobiol. 2013, 89, 97-102. [CrossRef] [PubMed]

9. Zhang, J.; Zhang, Y. Diurnal variations of chlorophyll fluorescence and $\mathrm{CO}_{2}$ exchange of biological soil crusts in different successional stages in the Gurbantunggut Desert of northwestern China. Ecol. Res. 2014, 29, 289-298. [CrossRef]

10. Thorlabs: Air-Spaced Doublet Collimators. Available online: https://www.thorlabs.com/newgrouppage9. cfm?objectgroup_id=1337 (accessed on 21 March 2018).

11. GWU-Lasertechnik. Spectrelle ${ }^{\circledR} 5000$ Compact High Resolution Echelle Spectrograph; GWU Group: Erftstadt, Germany, 2006.

12. Edmund Optics. Optical and Optical Instruments Catalog, Spring 2012; Edmund Optics: Barrington, IL, USA, 2012; p. 448.

13. Innovative Solutions for Your Application Needs; B\&W Tek: Newark, NJ, USA, 2012; pp. 11-27.

14. Thorlabs. CCS Series Spectrometer: Operational Manual. Available online: https://www.thorlabs.com/ Thorcat/18100/18143-D02.pdf (accessed on 21 March 2018).

15. Ibsen Photonics. How to Choose a Spectrometer. Available online: https://ibsen.com/technology/ spectrometer-tutorial/how-to-choose-a-spectrometer/ (accessed on 21 March 2018).

16. Ocean Optics. What's the Right Spectrometer for You? Available online: https://oceanoptics.com/wpcontent/uploads/What-is-the-Right-Spectrometer-for-You.pdf (accessed on 21 March 2018).

17. Czerny, M.; Turner, A.F. Über den astigmatismus bei spiegelspektrometern. Zeitschrift für Physik 1930, 61, 792-797. [CrossRef]

18. Utkin, A.B.; Vieira, S.; Marques da Silva, J.; Lavrov, A.; Leite, E.; Cartaxana, P. Compact low-cost detector for in vivo assessment of microphytobenthos using laser induced fluorescence. Opt. Spectrosc. 2013, 114, 471-477. [CrossRef]

19. Ocean Optics. Flame Optical Bench Options. Available online: https:/ / oceanoptics.com/product-details / flame-optical-bench-options / (accessed on 3 May 2018). 
20. Ocean Optics. Spectrometers. Available online: https://oceanoptics.com/wp-content/uploads/ OceanOptics_Spectrometers.pdf (accessed on 3 May 2018).

21. Toshiba. Toshiba CCD Linear Image Sensor TCD1304AP. Available online: https:/ / oceanoptics.com/wpcontent/uploads/Toshiba-TCD1304AP-CCD-array.pdf (accessed on 3 May 2018).

22. Sony. 2048-Pixel CCD Linear Sensor (B/W) for Single 5V Power Supply Bar-code Reader ILX511B. Available online: https: / / oceanoptics.com/wp-content/uploads/SONY-ILX511B.pdf (accessed on 3 May 2018).

23. Brach, E.J.; Molnar, J.M.; Jasmin, J.J. Detection of lettuce maturity and variety by remote sensing techniques. J. Agric. Eng. Res. 1977, 22, 45-54. [CrossRef]

24. Buschmann, C. Variability and application of the chlorophyll fluorescence emission ratio red/far red of leaves. Photosynth. Res. 2007, 92, 261-271. [CrossRef] [PubMed]

25. Lichtenthaler, H.K.; Rinderle, U. The role of chlorophyll fluorescence in the detection of stress conditions in plants. CRC Crit. Rev. Anal. Chem. 1988, 19, S29-S85. [CrossRef]

26. McMurtrey, J.E., III; Chappelle, E.W.; Kim, M.S.; Meisinger, J.J.; Corp, L.A. Distinguishing nitrogen fertilization levels in field corn (Zea mays L.) with actively induced fluorescence and passive reflectance measurements. Remote Sens. Environ. 1994, 47, 36-44. [CrossRef]

27. Subhash, N.; Mohanan, C.N. Curve fit analysis of chlorophyll fluorescence spectra: Application to nutrient stress detection in sunflower. Remote Sens. Environ. 1997, 60, 347-356. [CrossRef]

28. Schuerger, A.C.; Capelle, G.A.; Di Benedetto, J.A.; Mao, C.; Thai, C.M.; Evans, M.D.; Richards, J.T.; Blank, T.A.; Stryjewski, E.C. Comparison of two hyperspectral imaging and two laser induced fluorescence instruments for the detection of zinc stress and chlorophyll concentration in Bahia grass (Paspalum notatum Flugge). Remote Sens. Environ. 2003, 84, 572-588. [CrossRef]

29. Chappelle, E.W.; Wood, F.M.; McMurtrey, J.E., Jr.; Newcomb, W.W. Laser induced fluorescence of green plants. 1: A technique for the remote detection of plant stress and species differentiation. Appl. Opt. 1984, 23, 134-138. [CrossRef] [PubMed]

30. Hák, R.; Lichtenthaler, H.K.; Rinderle, U. Decrease of the chlorophyll fluorescence ratio F690/F730 during greening and development of leaves. Radiat. Environ. Biophys. 1990, 29, 329-336. [CrossRef] [PubMed]

31. Lichtenthaler, H.K.; Hák, R.; Rinderle, U. The chlorophyll fluorescence ratioF690/F730in leaves of different chlorophyll contents. Photosynth. Res. 1990, 25, 295-298. [CrossRef] [PubMed]

32. Lavrov, A.; Utkin, A.B.; Marques da Silva, J.; Vilar, R.; Santos, N.M.; Alves, B. Water stress assessment of cork oak leaves and maritime pine needles based on LIF spectra. Opt. Spectrosc. 2012, 112, 271-279. [CrossRef]

33. Cerovic, Z.G.; Goulas, Y.; Gorbunov, M.; Briantais, J.-M.; Camenen, L.; Moya, I. Fluorosensing of water stress in plants: Diurnal changes of the mean lifetime and yield of chlorophyll fluorescence, measured simultaneously and at distance with a LIDAR and a modified PAM-fluorimeter, in maize, sugar beet, and kalanchoë. Remote Sens. Environ. 1996, 58, 311-321. [CrossRef]

34. Kolber, Z.; Klimov, D.; Ananyev, G.; Rascher, U.; Berry, J.; Osmond, B. Measuring photosynthetic parameters at a distance: Laser induced fluorescence transient (LIFT) method for remote measurements of photosynthesis in terrestrial vegetation. Photosynth. Res. 2005, 84, 121-129. [CrossRef] [PubMed]

35. Gameiro, C.; Utkin, A.B.; Cartaxana, P.; Marques da Silva, J.; Matos, A.R. The use of laser induced chlorophyll fluorescence (LIF) as a fast and non-destructive method to investigate water deficit in Arabidopsis. Agric. Water Manag. 2016, 164, 127-136. [CrossRef]

36. Macintyre, H.L.; Geider, R.J.; Miller, D.C. Microphytobenthos: The ecological role of the "secret garden" of unvegetated, shallow-water marine habitats. I. Distribution, abundance and primary production. Estuaries 1996, 19, 186-201. [CrossRef]

37. Paterson, D.M.; Black, K.M. Water flow, sediment dynamics and benthic biology. Adv. Ecol. Res. 1999, 29, 155-193.

38. Eldridge, D.J.; Leys, J.F. Exploring some relationships between biological soil crusts, soil aggregation and wind erosion. J. Arid Environ. 2003, 53, 457-466. [CrossRef]

39. Adessi, A.; Cruz de Carvalho, R.; De Philippis, R.; Branquinho, C.; Marques da Silva, J. Microbial extracellular polymeric substances improve water retention in dryland biological soil crusts. Soil Biol. Biochem. 2018, 116, 67-69. [CrossRef]

40. Nagarkar, S.; Williams, G.A. Comparative techniques to quantify cyanobacteria dominated epilithic biofilms on tropical rocky shores. Mar. Ecol. Prog. Ser. 1997, 154, 281-291. [CrossRef] 
41. Round, F.E.; Palmer, J.D. Persistent, vertical-migration rhythms in benthic microflora. II. Field and laboratory studies on diatoms from the banks of the river Avon. J. Mar. Biol. Assoc. UK 1966, 46, 191-214. [CrossRef]

42. Paterson, D.M. The migratory behaviour of diatom assemblages in a laboratory tidal micro-ecosystem examined by low temperature scanning electron microscopy. Diatom Res. 1986, 1, 227-239. [CrossRef]

43. Marques da Silva, J.; Cruz, S.; Cartaxana, P. Inorganic carbon availability in benthic diatom communities: Photosynthesis and migration. Philos. Trans. R. Soc. B 2017, 372. [CrossRef] [PubMed]

44. Middelburg, J.J.; Barranguet, C.; Boschker, H.T.S.; Herman, P.M.J.; Moens, T.; Heip, C.H.R. The fate of intertidal microphytobenthos carbon: An in situ ${ }^{13}$ C-labeling study. Limnol. Oceanogr. 2000, 45, 1224-1234. [CrossRef]

45. Marques da Silva, J. Reconciling science and nature by means of the aesthetical contemplation of natural diversity. Rivista di Estetica 2015, 59, 93-113. [CrossRef]

46. Costanza, R.; d'Arge, R.; de Groot, R.; Farberk, S.; Grasso, M.; Hannon, B.; Limburg, K.; Naeem, S.; O'Neill, R.V.; Paruelo, J.; et al. The value of the world's ecosystem services and natural capital. Nature 1997, 387, 253-260. [CrossRef]

47. Belnap, J.; Kaltenecker, J.H.; Rosentreter, R.; Williams, J.; Leonard, S.; Eldridge, D. Biological Soil Crusts: Ecology and Management; Technical Reference 1730-2; Paterson, P., Ed.; United States Department of Interior: Denver, CO, USA, 2001.

48. Bartrons, M.; Catalan, J.; Casamayor, E.O. High bacterial diversity in epilithic biofilms of oligotrophic mountain lakes. Microb. Ecol. 2012, 64, 860-869. [CrossRef] [PubMed]

49. Rickard, A.H.; McBain, A.J.; Stead, A.T.; Gilbert, P. Shear rate moderates community diversity in freshwater biofilms. Appl. Environ. Microbiol. 2004, 70, 7426-7435. [CrossRef] [PubMed]

50. Besemer, K. Biodiversity, community structure and function of biofilms in stream ecosystems. Res. Microbiol. 2015, 166, 774-781. [CrossRef] [PubMed]

51. Cutler, N.A.; Chaput, D.L.; Oliver, A.E.; Viles, H.A. The spatial organization and microbial community structure of an epilithic biofilm. FEMS Microbiol. Ecol. 2015, 93, fiu027. [CrossRef] [PubMed]

52. Kusumi, A.; Li, X.; Osuga, Y.; Kawashima, A.; Gu, J.-D.; Nasu, M.; Katayama, Y. Bacterial communities in pigmented biofilms formed on the swandstone bas-relief walls of the Bayon temple, Angkor Thom, Cambodia. Microbes Environ. 2013, 28, 422-431. [CrossRef] [PubMed]

53. Zimermann, J.; Gonzalez, J.M.; Saiz-Jimenez, C. Epilithic biofilms in Saint Callixtus Catacombs (Rome) harbour a broad spectrum of Acidobacteria. Antonie van Leeuwenhoek 2006, 89, 203-208. [CrossRef] [PubMed]

54. Ereshefsky, M.; Pedroso, M. Rethinking evolutionary individuality. Proc. Natl. Acad. Sci. USA 2015, 112, 10126-10132. [CrossRef] [PubMed]

55. Marques da Silva, J.; Casetta, E. Why a species-based approach to biodiversity is not enough. Lessons from multispecies biofilms. In From Assessing to Conserving Biodiversity; Casetta, E., Vecchi, D., Marques da Silva, J., Eds.; Springer: Dordrecht, The Netherlands, in press.

56. Kromkamp, J.; Barranguet, C.; Peene, J. Determination of microphytobenthos PSII quantum efficiency and photosynthetic activity by means of variable chlorophyll fluorescence. Mar. Ecol. Prog. Ser. 1998, 162, 45-55. [CrossRef]

57. Richards, J.T.; Schuerger, A.C.; Capelle, G.; Guikema, J.A. Laser-induced fluorescence spectroscopy of dark and light-adapted bean (Phaseolus vulgaris L.) and wheat (Triticum aestivum L.) plants grown under three irradiance levels and subjected to fluctuating lighting conditions. Remote Sens. Environ. 2003, 84, 323-341. [CrossRef]

58. Anderson, B.; Buah-Bassuah, P.; Tetteh, J. Using violet laser-induced chlorophyll fluorescence emission spectra for crop yield assessment of cowpea (Vigna unguiculate (L) Walp) varieties. Meas. Sci. Technol. 2004, 15, 1255-1265. [CrossRef]

59. Ananyev, G.; Kolber, Z.S.; Klimov, D.; Falkowski, P.G.; Berry, J.A.; Raschers, U.; Martin, R.; Osmond, B. Remote sensing of heterogeneity in photosynthetic efficiency, electron transport and dissipation of excess light in Populus deltoides stands under ambient and elevated $\mathrm{CO}_{2}$ concentrations, and in a tropical forest canopy, using a new laser-induced fluorescence transient device. Glob. Chang. Biol. 2005, 11, 1195-1206. [CrossRef]

60. Pieruschka, R.; Klimov, D.; Kolber, Z.; Berry, J.A. Monitoring of cold and light stress impact on photosynthesis by using laser induced fluorescence transient (LIFT) approach. Funct. Plant Biol. 2010, 37, 395-402. [CrossRef] 
61. Vieira, S. Photosynthetic Metabolism in Microphytobenthos: Modulation by Temperature and Dissolved Inorganic Carbon. Ph.D. Thesis, University of Lisbon, Lisbon, Portugal, 2016.

62. Vieira, S.; Lavrov, A.; Utkin, A.; Santos, A.; Vilar, R.; Marques da Silva, J.; Cartaxana, P. Effects of intertidal microphytobenthos migration on biomass determination via laser-induced fluorescence. Mar. Ecol. Prog. Ser. 2011, 432, 45-52. [CrossRef]

63. Launeau, P.; Méléder, V.; Verpoorter, C.; Barillé, L.; Kazemipour-Ricci, F.; Giraud, M.; Jesus, B.; Le Menn, E. Microphytobenthos biomass and diversity mapping at different spatial scales with a hyperspectral optical model. Remote Sens. 2018, 10, 716. [CrossRef]

64. Myneni, R.B.; Hall, F.G.; Sellers, P.G.; Marshak, A.L. The interpretation of spectral vegetation indexes. IEEE Trans. Geosci. Remote Sens. 1995, 33, 481-486. [CrossRef]

65. Brito, A.C.; Benyoucef, I.; Jesus, B.; Brotas, V.; Gernez, P.; Mendes, C.R.; Launeau, P.; Peixe Dias, M.; Barillé, L. Seasonality of microphytobenthos revealed by remote-sensing in a South European estuary. Cont. Shelf Res. 2013, 66, 83-91. [CrossRef]

66. Kuczynska, P.; Jemiola-Rzeminska, M.; Strzalka, K. Photosynthetic pigments in diatoms. Mar. Drugs 2015, 13, 5847-5881. [CrossRef] [PubMed]

67. Pinevich, A.V.; Averina, S.G.; Velichko, N.V. Another view on the role of photosynthetic pigments in taxonomy of oxygenic-phototrophic bacteria: Proposed rejection of the order Prochlorales Florenzano, Balloni, and Materassi 1986 (Emend. Burger-Wiersma, Stal, and Mur 1989), the family Prochloraceae Florenzano, Balloni, and Materassi 1986, and the family Prochlorotrichaceae Burger-Wiersma, Stal, and Mur 1989. Int. J. Syst. Bacteriol. 1997, 47, 1264-1267.

68. Beutler, M. Spectral Fluorescence of Chlorophyll and Phycobilins as an In-Situ Tool of Phytoplankton Analysis-Models, Algorithms and Instruments. Ph.D. Thesis, Christian-Albrechts-Universität zu Kiel, Kiel, Germany, 2003.

69. Quantel. Ultra (50-100 mJ) Lamp Pumped Solid State Laser. Available online: http:/ / www.quantel-laser. com/en/products/item/ultra-50-100-mj--134.html (accessed on 12 September 2018).

70. Van der Weij-De Wit, C.D.; Doust, A.B.; van Stokkum, I.H.M.; Dekker, J.P.; Wilk, K.E.; Curmi, P.M.G.; Scholes, G.D.; van Grondelle, R. How energy frunnels from the phycoerythrin antenna complex to photosystem I and photosystem II in cryptophyte Rhodomonas CS24 cells. J. Phys. Chem. B 2006, 110, 25066-25073. [CrossRef] [PubMed]

71. Pizarro, S.A.; Sauer, K. Spectroscopic study of the light-harvesting protein C-phycocyanin associated with colorless linker peptides. Photochem. Photobiol. 2001, 73, 556-563. [CrossRef]

72. Raanan, H.; Oren, N.; Treves, H.; Keren, N.; Ohad, I.; Berkowicz, S.M.; Hagemann, M.; Koch, M.; Shotland, Y.; Kaplan, A. Towards clarifying what distinguishes cyanobacteria able to resurrect after desiccation from those that cannot: The photosynthetic aspect. Biochim. Biophys. Acta 2016, 1857, 715-722. [CrossRef] [PubMed]

73. Limão, F.M.; Maciel, M.J. Tróia. Wiley Online Library. Available online: https://doi.org/10.1002/ 9781444338386.wbeah30227 (accessed on 21 March 2018).

74. Solhaug, K.A.; Gauslaa, Y.; Nybakken, L.; Bilger, W. UV-induction of sun-screening pigments in lichens. New Phytol. 2003, 158, 91-100. [CrossRef]

75. Thorne, K.M.; Elliott-Fisk, D.L.; Freeman, C.M.; Bui, T.-V.D.; Powelson, K.W.; Janousek, C.N.; Buffington, K.J.; Takekawa, J.Y. Are coastal managers ready for climate change? A case study from estuaries along the Pacific coast of the United States. Ocean Coast. Manag. 2017, 143, 38-50. [CrossRef]

76. Huang, J.; Yu, H.; Guan, X.; Wang, G.; Guo, R. Accelerated dryland expansion under climate change. Nat. Clim. Chang. 2016, 6, 166-171. [CrossRef]

77. Chamizo, S.; Mugnai, G.; Rossi, F.; Certini, G.; De Philippis, R. Cyanobacteria inoculation improves soil stability and fertility on different textured soils: Gaining insights for applicability in soil restoration. Front. Environ. Sci. 2018, 6, 49. [CrossRef]

78. Joiner, J.; Yoshida, Y.; Vasilkov, A.P.; Yoshida, Y.; Corp, L.A.; Middleton, E.M. First observations of global and seasonal terrestrial chlorophyll fluorescence from space. Biogeosciences 2011, 8, 637-651. [CrossRef]

79. Cartaxana, P.; Vieira, S.; Ribeiro, L.; Rocha, R.; Cruz, S.; Calado, R.; Marques da Silva, J. Effects of elevated temperature and $\mathrm{CO}_{2}$ on intertidal microphytobenthos. BMC Ecol. 2015, 15, 10. [CrossRef] [PubMed]

80. Escolar, C.; Martínez, I.; Bowker, M.A.; Maestre, F.T. Warming reduces the growth and diversity of biological soil crusts in a semi-arid environment: Implications for ecosystem structure and functioning. Philos. Trans. $R$. Soc. B 2012, 367, 3087-3099. [CrossRef] [PubMed] 
81. LDI Innovation. Spectral Fluorescence Signatures. Available online: http://ldi-innovation.eu/documents/ SFStechnique.pdf (accessed on 12 September 2018).

82. STORM Consortium. Early Detection of Biological Infestation: Experiments Started at Tróia. Available online: http:/ / www.storm-project.eu/early-detection-of-biological-infestation-experiments-started-attroia/ (accessed on 3 May 2018).

83. Utkin, A.B.; Chaves, P.; Fernandes, L.; Pinto, I.V.; Revez, M.J. LIF and SFS techniques for early detection of biofilms harmful for cultural heritage. In Proceedings of the 2018 International Conference Laser Optics (ICLO), St. Petersburg, Russia, 4-8 June 2018; p. 275. [CrossRef]

84. Strieth, D.; Ulber, R.; Muffler, K. Application of phototrophic biofilms: From fundamentals to processes. Bioprocess Biosyst. Eng. 2018, 41, 295-312. [CrossRef] [PubMed]

85. McCormick, A.J.; Bombelli, P.; Scott, A.M.; Philips, A.J.; Smith, A.G.; Fisher, A.C.; Howe, C.J. Photosynthetic biofilms in pure culture harness solar energy in a mediatorless bio-photovoltaic cell (BPV) system. Energy Environ. Sci. 2011. [CrossRef]

86. Vieira, S.; Cartaxana, P.; Máguas, C.; Marques da Silva, J. Photosynthesis in estuarine intertidal microphytobenthos is limited by inorganic carbon availability. Photosynth. Res. 2016, 128, 85-92. [CrossRef] [PubMed]

87. Li, T.; Podola, B.; de Beer, D.; Melkonian, M. A method to determine photosynthetic activity from oxygen microsensor data in biofilms subjected to evaporation. J. Microbiol. Methods 2015, 117, 100-107. [CrossRef] [PubMed]

88. Roeselers, G.; van Loosdrecht, M.C.M.; Muyzer, G. Phototrophic biofilms and their potential applications. J. Appl. Phycol. 2008, 20, 227-235. [CrossRef] [PubMed]

89. Kohl, A.; Fillardet, T.; Moisan, H.; Brousse, E. Progress of laser diode arrays operating under harsh conditions. Proc. SPIE 2010, 7835, 78350Q. [CrossRef]

(C) 2018 by the authors. Licensee MDPI, Basel, Switzerland. This article is an open access article distributed under the terms and conditions of the Creative Commons Attribution (CC BY) license (http:// creativecommons.org/licenses/by/4.0/). 